\title{
Intestinal immunity of rats with colon cancer is modulated by oligofructose-enriched inulin combined with Lactobacillus rhamnosus and Bifidobacterium lactis
}

\author{
Monika Roller ${ }^{1}$, Angelo Pietro Femia ${ }^{2}$, Giovanna Caderni ${ }^{2}$, Gerhard Rechkemmer ${ }^{1} \dagger$ and \\ Bernhard Watzl ${ }^{1 *}$ \\ ${ }^{1}$ Institute of Nutritional Physiology, Federal Research Centre for Nutrition and Food, Haid-und-Neu-Str. 9, \\ 76131 Karlsruhe, Germany \\ ${ }^{2}$ Department of Pharmacology, University of Florence, 6 Viale Pieraccini, 50139 Florence, Italy
}

(Received 22 April 2004 - Revised 11 August 2004 - Accepted 16 August 2004)

Probiotics (PRO) are known to modulate immunity in animals and human subjects and to inhibit colon carcinogenesis in experimental models, but the effects of synbiotics (SYN) are not well understood. Therefore, the effects of PRO (Lactobacillus rhamnosus GG and Bifidobacterium lactis Bb12), PRE (inulin-based enriched with oligofructose, $100 \mathrm{~g} / \mathrm{kg}$ ) and SYN (combination of PRO and PRE) on the immune system of rats were investigated in the azoxymethane (AOM)-induced colon cancer model. After 33 weeks, rats with and without AOM treatment were killed and immune cells were isolated from spleen, mesenterial lymph nodes (MLN) and Peyer's patches (PP). AOM treatment significantly reduced natural killer (NK) cell-like cytotoxicity in control rats and in PRO- and PRE-supplemented rats. SYN supplementation prevented the AOM-induced suppression of NK cell-like cytotoxicity in PP compared with control rats $(P<0.01)$. SYN and PRE supplementation stimulated IL-10 production in PP in these rats $(P<0 \cdot 01)$ and in MLN of rats not treated with AOM $(P<0.05)$. Interferon- $\gamma$ production in PP was decreased by PRO supplementation (PRO and SYN groups combined; $P<0.05$ ). Proliferative responsiveness of lymphocytes (PP) from AOM-treated rats was suppressed in SYN-supplemented rats $(P<0 \cdot 01)$. Overall, SYN supplementation in carcinogen-treated rats primarily modulated immune functions in the PP, coinciding with a reduced number of colon tumours. PRE and PRO provided in combination as SYN may contribute to the suppression of colon carcinogenesis by modulating the gut-associated lymphoid tissue.

Immune system: Colon cancer: Probiotic: Prebiotic: Synbiotic: Rat

Diet plays an important role in cancer prevention by modifying the activities of a number of protective systems, including the immune system (Greenwald et al. 2001). Among the different immune cell types involved in recognition of tumour cells are the natural killer (NK) cells. Through their production of immunoregulatory cytokines and their cytotoxic effects, NK cells are primary effector cells in tumour cell elimination (Smyth et al. 2001). They comprise up to $15 \%$ peripheral blood lymphocytes and occur in liver, spleen, intestinal tissue and lymph nodes. Depletion of NK cells in vivo leads to enhanced tumour formation in several mouse tumour models (Smyth et al. 2001). In addition, cancer patients who had recurrences within 2 years of surgery had significantly lower preoperative NK cell cytotoxicity than recurrence-free patients (Tartter et al. 1987). Results from a prospective cohort study have indicated that in healthy human subjects a low NK cell cytotoxic activity is associated with an enhanced risk of epithelial cancer development in later life (Imai et al. 2000). These results suggest that a high NK cell cytotoxicity is associated with lower cancer rates.

Increasing evidence from experimental and human studies suggests that probiotics (PRO) modulate the host resistance against intestinal infections as well as a number of immune cell functions (Cross, 2002; Teitelbaum \& Walker, 2002). Several studies in animals (Gill et al. 2000; Gill \& Cross, 2002) and human subjects (Gill et al. 2001; Gill \& Cross, 2002) have shown that PRO specifically enhance NK cell cytotoxicity in blood and spleen. Enhanced NK cell cytotoxicity through supplementation with Lactobacillus casei Shirota was associated with delayed carcinogenesis in a 3-methylcholanthrene-induced

Abbreviations: AOM, azoxymethane; GALT, gut-associated lymphoid tissue; IFN, interferon; MLN, mesenterial lymph nodes; NK, natural killer; OD, optical density; PP, Peyer's patches; PRE, prebiotics; PRO, probiotics; SYN, synbiotics.

* Corresponding author: Dr Bernhard Watzl, fax + 497216625 400, email bernhard.watzl@bfe.uni-karlsruhe.de

$\dagger$ Present address: Technical University of Munich, Department of Food and Nutrition, Hochfeldweg 1, 85354 Freising-Weihenstephan, Germany. 
carcinogenesis model (Takagi et al. 2001). In NK-deficient mice, however, it failed to suppress tumourigenesis (Takagi et al. 2001).

In addition to PRO, prebiotics (PRE) are another potentially cancer-protective food constituent. PRE are nondigestible carbohydrates that selectively stimulate the growth of bacteria in the colon (van Loo et al. 1999). Several studies have shown reduced tumour numbers in the colon of rats supplemented with PRE (Reddy 1998, 1999; Pool-Zobel et al. 2002; Verghese et al. 2002). We have recently shown that the administration of PRE alone or in combination with PRO reduced the number of colon tumours in rats treated with the carcinogen azoxymethane (AOM; Femia et al. 2002).

At present, the effects of PRE on the immune system have only been investigated in a few studies (Schley \& Field, 2002). Studies using oligofructose in animals reported increased leukocyte and/or lymphocyte numbers in the gut-associated lymphoid tissue (GALT) as well as elevated numbers of Peyer's patches (PP; Pierre et al. 1997). In a short-term study, we have shown that at the level of GALT, PRE, as well as the combined administration of PRE and PRO (synbiotics, SYN), significantly stimulated secretory IgA and IL-10 production (Roller et al. 2004).

The present study investigated the long-term effects of PRO, PRE and SYN on the immune system of rats, focusing primarily on GALT. We hypothesized that rats exposed to the colon carcinogen AOM and treated with PRO or PRE alone or in combination would differ in their immune responses. The same rats were used in the carcinogenesis study of Femia et al. (2002). As PRO, we applied two strains of lactobacilli and bifidobacteria that have been used extensively in experimentally induced colon cancer studies (de Roos \& Katan, 2000; Wollowski et al. 2001). NK cell-like cytotoxicity was assessed with cells isolated from PP, mesenterial lymph nodes (MLN) and spleen. All immunological measurements were done 31 weeks after the AOM treatment, a time-point when the AOM-treated rats had developed adenomas and carcinomas in the colon.

\section{Materials and methods}

\section{Materials}

AOM was purchased from Sigma (Milan, Italy). Dietary components were purchased from Piccioni (Gessate, Milan, Italy). Raftilose Synergy $1{ }^{\circledR}$ was provided by Orafti (Tienen, Belgium). This PRE is an oligofructoseenriched inulin which is a 1:1 mixture of long-chain and short-chain fractions of inulin, a $\beta(2-1)$-fructan extracted from chicory (Cichorium intybus) roots. The PRO Lactobacilli rhamnosus GG and Bifidobacteria lactis Bb12 were provided by Valio (Helsinki, Finland) and purchased from Chr. Hansen (Horsholm, Denmark) respectively. They were provided as freeze-dried powder in sealed packets, which contained about $4 \times 10^{11}$ colony forming units/g (L. rhamnosus GG) and about $3 \times 10^{10}$ colony forming units/g (B. lactis Bb12). The bacteria were kept at $-20^{\circ} \mathrm{C}$ until used. The concentrations of L. rhamnosus GG and B. lactis Bb12 in the diet were evaluated as described elsewhere (Femia et al. 2002).

\section{Animals and treatments}

Male Fischer 344 rats (Nossan, Correzzana, Milan, Italy) aged 4-5 weeks were used for the present study. The experimental protocol was approved by the Commission for Animal Experimentation of the Ministry of Health, Rome, Italy. Details of the treatment have been described earlier (Femia et al. 2002). Briefly, rats were randomly allocated to the following experimental groups. (1) Control group ( $n$ 32): rats were fed on a high-fat diet based on the AIN76 diet (American Institute of Nutrition, 1977), modified to contain a high fat level ( $230 \mathrm{~g}$ maize oil $/ \mathrm{kg}$ diet) and a low cellulose level $(20 \mathrm{~g} / \mathrm{kg})$ to model a diet typical of western human populations at high risk of colon cancer (Femia et al. 2002). The sources of carbohydrate in this diet were sucrose $(361 \mathrm{~g} / \mathrm{kg})$ and maltodextrin $(100 \mathrm{~g} / \mathrm{kg})$. (2) PRO group ( $n$ 32): rats were fed on the same high-fat diet as the control group, but supplemented with L. rhamnosus GG $\left(5.0 \times 10^{8}\left(\mathrm{SD} 1.3 \times 10^{8}\right)\right.$ colony forming units/g diet $)$ and B. lactis $\mathrm{Bb} 12\left(5.5 \times 10^{8}\left(\mathrm{SD} 2.4 \times 10^{8}\right)\right.$ colony forming units/g diet). (3) PRE group ( $n$ 33): rats were fed with the same high-fat diet as the control group, but maltodextrin was replaced by $100 \mathrm{~g}$ Raftilose Synergy $1^{\circledR}$ (Orafti) $/ \mathrm{kg}$. (4) SYN group ( $n$ 32): rats were fed on the same high-fat diet as the PRE group supplemented with L. rhamnosus GG and B. lactis Bb12 to provide about $5 \times 10^{8}$ colony forming units of each strain/g diet as in the PRO group. Food and water were offered ad libitum. Diets were prepared every 2 weeks, divided into aliquots and frozen at $-20^{\circ} \mathrm{C}$. Ten days after starting to feed the experimental diets, all rats were administered AOM $(15 \mathrm{mg} / \mathrm{kg}$ two times subcutaneously, 1 week apart), except that four to five animals in each dietary group were treated with saline $(9 \mathrm{~g} \mathrm{NaCl} / \mathrm{l})$ instead of AOM and served as the control for the carcinogen treatment. After feeding the experimental diets for 33 weeks, the rats were killed by $\mathrm{CO}_{2}$ asphyxiation. While for the assessment of tumour incidence all the thirty-two to thirtythree rats per group exposed to AOM were investigated, for the immunological investigations fifteen AOM-exposed rats randomly chosen from each group were used. After the rats were killed, spleens, MLN and Peyer's patches (PP) were immediately sent $\left(\right.$ at $4^{\circ} \mathrm{C}$ ) by courier from Florence, Italy, to Karlsruhe, Germany, so that tissues were processed within $24 \mathrm{~h}$ of killing.

\section{Preparation of immune cell suspensions}

For the preparation of cell suspensions from spleens, MLN and PP, Roswell Park Memorial Institute medium-1640 containing heat-inactivated fetal bovine serum $(50 \mathrm{ml} / \mathrm{l})$, L-glutamine $(2 \mathrm{mmol} / \mathrm{l})$, penicillin $\left(1 \times 10^{5} \mathrm{U} / \mathrm{l}\right)$, streptomycin $(100 \mathrm{mg} / \mathrm{l})$ and HEPES $(25 \mathrm{mmol} / \mathrm{l})$ was used (all components were purchased from Life Sciences, Eggenstein-Leopoldshafen, Germany). Technical details of the cell isolation procedure have been described earlier (Watzl et al. 1999).

\section{Fluorescence staining of lymphocyte subpopulations}

The expression of cell surface markers on the immune cells of spleens and MLN was investigated by immunofluorescence 
as described earlier (Watzl et al. 1999). Briefly, $100 \mu \mathrm{l}$ cell suspension $\left(1 \times 10^{10}\right.$ cells $\left./ 1\right)$ was incubated for $30 \mathrm{~min}$ at $4^{\circ} \mathrm{C}$ with $5 \mu \mathrm{l}$ phycoerythrin-conjugated mouse anti-rat monoclonal antibodies to CD4 (Caltag, Hamburg, Germany) and fluorescein-conjugated mouse anti-rat monoclonal antibodies to CD8 (Caltag). In the control tube, cells were incubated with appropriate isotype controls (Caltag). Cells were fixed after staining with paraformaldehyde $(10 \mathrm{ml} / \mathrm{l}$; SigmaAldrich, Steimheim, Germany). Analysis was carried out on a FACSCalibur flow cytometer (BD Biosciences, Heidelberg, Germany).

\section{Cytotoxicity of natural killer cells}

A flow cytometric method was used to assess the NK cell activity of immune cells of spleen, MLN and PP. Cells from the mouse Moloney leukaemia cell line, YAC-1, were used as target cells. Briefly, $1 \times 10^{9}$ YAC- 1 cells/ 1 were labelled with $10 \mu \mathrm{l}$ 3,3'-dioctadecycloxacarbocyanin perchlorate $(3 \mathrm{mmol} / \mathrm{l}$; Molecular Probes, Leiden, Netherlands) and incubated for $20 \mathrm{~min}$ at $37^{\circ} \mathrm{C}$. Cell suspensions from PP, MLN and spleens at a density of $5 \times 10^{9}$ cells $/ 1$ were pipetted in triplicate into tubes to which appropriately diluted 3,3'-dioctadecycloxacarbocyanin perchloratelabelled target cells were added for final effector:target ratios of $12 \cdot 5: 1$ and $6 \cdot 25: 1$. Finally, $20 \mu \mathrm{l}$ propidium iodide (525 mg/l; Molecular Probes) was added to each tube and cells were incubated for $135 \mathrm{~min}$ at $37^{\circ} \mathrm{C}$ and $5 \% \mathrm{CO}_{2}$. The percentage of double-stained target cells was quantified and the lytic activity was calculated as the percentage of dead target cells in the test samples minus the percentage of dead target cells in the control samples without effector cells (Chang et al. 1993).

\section{Lymphocyte proliferation}

Ex vivo proliferative responsiveness of lymphocytes isolated from spleen, MLN (each $5 \times 10^{9}$ cells/l) and PP $\left(7 \times 10^{9}\right.$ cells $\left./ 1\right)$ to the mitogen concanavalin A $(1 \mathrm{mg} / \mathrm{l}$; Sigma-Aldrich) for $72 \mathrm{~h}$ at $37^{\circ} \mathrm{C}, 5 \% \mathrm{CO}_{2}$ and $95 \%$ humidity was determined by ELISA (Cellular Proliferation ELISA kit; Roche Diagnostics, Mannheim, Germany). Proliferative responses were expressed as the net absorbance values (absorbance ${ }_{\mathrm{A} 450 \mathrm{~nm}-\mathrm{A} 650 \mathrm{~nm}}$ of pulse-labelled cells - absorbance ${ }_{\mathrm{A} 450 \mathrm{~nm}-\mathrm{A} 650 \mathrm{~nm}}$ of unlabelled cells) and expressed as optical density (OD) units.

\section{Cytokines}

Splenocytes $\left(100 \mu \mathrm{l} ; 1 \times 10^{9}\right.$ cells/l for interferon (IFN)- $\gamma$ and $5 \times 10^{9}$ cells/l for IL-10), MLN $\left(100 \mu \mathrm{l} ; 1 \times 10^{9}\right.$ cells $/ 1$ for IFN- $\gamma$ and $5 \times 10^{9}$ cells/l for IL-10) and PP $\left(100 \mu \mathrm{l} ; 5 \times 10^{9}\right.$ cells/ 1 for IFN- $\gamma$ and IL-10) were cultivated in duplicate in flat-bottomed ninety-six-well microtitre plates and stimulated by $100 \mu \mathrm{l}$ concanavalin A $(5 \mathrm{mg} / \mathrm{l})$ for $24 \mathrm{~h}$ at $37^{\circ} \mathrm{C}, 5 \% \mathrm{CO}_{2}$ and $95 \%$ humidity. IFN- $\gamma$ and IL-10 in the supernatant fractions were measured by commercial ELISA kits (OptEIA ${ }^{\mathrm{TN}}$; BD Pharmingen, Heidelberg, Germany) following the manufacturer's instructions.

\section{Statistical evaluation of the data}

Results are reported as mean values and standard deviations. Differences between control and treatment groups were tested for significance by one-way ANOVA with the Tukey-Kramer test for comparison of individual mean values when appropriate. Differences between AOM-treated and non-treated animals per group were analysed by using unpaired Student's $t$ test. To assess correlations between immunological markers and numbers of tumours, Pearson correlation coefficients were computed. Values of $P<0.05$ were considered significant. All statistical calculations were performed with the StatView program (1998; SAS Institute Inc., Cary, NC, USA).

\section{Results}

\section{Body weight and feed intake}

Supplementation of the control diet with PRO, PRE and the combined application of PRO and PRE (SYN) for 33 weeks had no significant effect on feed intake and weight gain when compared with the control group (results not shown). The mean weight of the rats at the beginning of the experiment was 108.8 (SD 12.2) g ( $n$ 129). At death, the mean weight was similar among dietary groups (479.5 (SD 34.0) g).

\section{Tumour-suppressive effect of dietary treatment}

We have already reported the tumour incidence in the present study (Femia et al. 2002). AOM-treated rats receiving Raftilose Synergy $1^{\circledR}$ (Orafti; PRE and SYN groups) had a significantly lower number of tumours (adenomas and carcinomas; $P<0 \cdot 001$ ) than rats without the PRE supplement (control and PRO groups). The PRO treatment (PRO and SYN groups) slightly reduced the number of carcinomas $(P=0.079)$ when compared with control and PRE groups (Femia et al. 2002).

\section{Natural killer cell activity}

Because NK cells were not quantified in the cell suspensions of spleen, PP and MLN, in the following we use the term NK cell-like activity. In control and PRO-supplemented rats the AOM treatment reduced NK cell-like activity in all tissues investigated (Table 1). PRE (PP) and SYN (PP and spleen) treatment prevented the AOMinduced tumour-associated suppression of NK cell-like cytotoxicity measurable in control and PRO-fed rats. The PP of SYN-supplemented rats treated with AOM had significantly higher NK cell-like activity compared with control or PRO-fed rats (Table 1). In addition, NK cell-like cytotoxic function was stimulated in the spleen of rats not exposed to the carcinogen supplementation with PRE. However, no significant correlation was observed between the total number of adenomas or carcinomas in the colon and the cytotoxic activity of NK cells independent of the dietary group (results not shown). 
Table 1. Natural killer cell-like activity (effector:target ratio $12.5: 1.0)$ of mononuclear cells isolated from spleen, mesenterial lymph nodes or Peyer's patches from rats fed for 33 weeks on a probiotic, prebiotic, synbiotic or control diet $\$$ \&l

(Mean values and standard deviations)

\begin{tabular}{|c|c|c|c|c|c|c|c|c|}
\hline \multirow[b]{2}{*}{ AOM } & \multicolumn{2}{|c|}{ Control } & \multicolumn{2}{|c|}{ Probiotic } & \multicolumn{2}{|c|}{ Prebiotic } & \multicolumn{2}{|c|}{ Synbiotic } \\
\hline & Mean & SD & Mean & SD & Mean & SD & Mean & SD \\
\hline \multicolumn{9}{|c|}{ Spleen } \\
\hline- & $31 \ddagger$ & 4 & $39 \ddagger \neq \ddagger$ & 2 & $43^{\star} \ddagger \ddagger \ddagger \ddagger$ & 10 & 33 & \\
\hline+ & 22 & 8 & 23 & 10 & 25 & 8 & 28 & 10 \\
\hline \multicolumn{9}{|c|}{ Mesenterial lymph nodes } \\
\hline- & 29 & 5 & $36 \neq \ddagger$ & 6 & 30 & 5 & 33 & \\
\hline+ & 27 & 8 & 26 & 7 & 27 & 6 & 27 & \\
\hline \multicolumn{9}{|c|}{ Peyer's patches } \\
\hline- & $39 \neq \ddagger$ & 2 & $47 \ddagger \ddagger \ddagger$ & 4 & 39 & 4 & 45 & \\
\hline+ & 32 & 6 & 34 & 8 & 39 & 8 & $42^{\star *} \dagger$ & \\
\hline
\end{tabular}

AOM, azoxymethane.

Mean values were significantly different from those of the control group: ${ }^{\star} P<0.05,{ }^{*} P<0.0$.

Mean value was significantly different from that of the prebiotic group: $\dagger P<0.05$.

Mean values were significantly different from those of the AOM-treated group: $\ddagger P<0.057, \ddagger \ddagger P<0.05, \ddagger \ddagger \ddagger P<0.01, \ddagger \ddagger \ddagger \ddagger P<0.001$.

$\S$ Rats were non-exposed (four to five per group) or exposed to the carcinogen AOM (fifteen per group) at the beginning of the dietary treatment. For details of diets and procedures, see p. 932.

$\|$ Results are expressed as a percentage of lysed target cells.

\section{Cytokine production}

IFN and IL-10 production from ex vivo activated cells isolated from spleen, MLN and PP were measured. IL-10 production in $\mathrm{PP}$ of AOM-treated rats was significantly enhanced in rats supplemented with PRE and SYN (Table 2). This stimulatory effect on IL-10 production was also seen in the MLN of rats not treated with the carcinogen but supplemented with the PRE (PRE and SYN combined $v$. control and PRO combined: 141.9 (SD 38.8) v. 76.3 (SD 20.3) ng/l, $P<0.05$ ). IL-10 production by splenocytes was neither affected by dietary supplements nor by AOM-treatment.

In contrast, the capacity to produce IFN- $\gamma$ was only affected by the dietary treatment in the PP of rats not exposed to AOM (results not shown). Rats supplemented with the PRO (PRO and SYN) had significantly lower IFN- $\gamma$ production when compared with control and PRE rats $(1.4(\mathrm{SD} 0.5)$ v. $2.2(\mathrm{SD} 0.7) \mu \mathrm{g} / \mathrm{l} ; P<0.05)$. There was a trend towards an increased IL-10:IFN- $\gamma$ ratio in PP lymphocytes of rats not exposed to the carcinogen (control 0.135 (SD 0.055), PRO 0.135 (SD 0.070), PRE 0.145 (SD 0.045 ), SYN 0.259 (SD 0.095); $P=0.0565$ ). No significant effects were observed in spleen and MLN.

\section{Lymphocyte subpopulations}

Spleen and MLN lymphocytes were analysed for the percentage of $\mathrm{CD}^{+}{ }^{+}$T-helper and $\mathrm{CD}^{+}{ }^{+}$T-suppressor lymphocytes. AOM treatment significantly reduced CD4:CD8 lymphocytes ratio in spleen and MLN (Table 3). In both tissues this was caused by an increase in the number of CD8-positive lymphocytes $(P<0 \cdot 05$; results not shown). In rats without $A O M$ treatment $P R E$ reduced the CD4:CD8 ratio in spleens (Table 3) without significantly changing the percentage of CD4 or CD8 (results not shown). Cells isolated from PP were not available for the determination of the lymphocyte subpopulations.

\section{Lymphocyte proliferation}

The treatment with the carcinogen did not affect lymphocyte proliferation compared with untreated rats. In AOMtreated rats no significant effects of the dietary intervention were observed in spleens and MLN (results not shown). In PP, however, the SYN treatment significantly reduced lymphocyte proliferation (control 1.4 (SD 0.5) $\mathrm{OD}_{450}$, PRO 1.2 (SD 0.3) $\mathrm{OD}_{450}$, PRE 1.3 (SD 0.4) $\mathrm{OD}_{450}$, SYN 0.6 (SD 0.4) $\mathrm{OD}_{450} ; P<0.01 v$. control, PRO and PRE).

\section{Discussion}

The results of the present study demonstrate that long-term supplementation with PRE and with PRE combined with PRO modulates immune functions in GALT, while PRO

Table 2. IL-10 (ng/l) production of mononuclear cells isolated from spleen, mesenterial lymph nodes and Peyer's patches from rats fed for 33 weeks with a probiotic, prebiotic, synbiotic or control diet§ (Mean values and standard deviations)

\begin{tabular}{|c|c|c|c|c|c|c|c|c|}
\hline \multirow[b]{2}{*}{ AOM } & \multicolumn{2}{|c|}{ Control } & \multicolumn{2}{|c|}{ Probiotic } & \multicolumn{2}{|c|}{ Prebiotic } & \multicolumn{2}{|c|}{ Synbiotic } \\
\hline & Mean & SD & Mean & SD & Mean & SD & Mean & SD \\
\hline \multicolumn{9}{|c|}{ Spleen } \\
\hline- & 529 & 180 & 644 & 201 & 956 & 480 & 722 & 138 \\
\hline+ & 687 & 139 & 748 & 147 & 677 & 200 & 646 & 272 \\
\hline \multicolumn{9}{|c|}{ Mesenterial lymph nodes } \\
\hline- & 83‡ & 21 & $69 \ddagger$ & 20 & $144^{*}$ & 26 & $140^{*}$ & 56 \\
\hline+ & 136 & 40 & 138 & 38 & 178 & 44 & 166 & 60 \\
\hline \multicolumn{9}{|c|}{ Peyer's patches } \\
\hline- & 270 & 55 & 220 & 151 & 297 & 64 & 308 & 64 \\
\hline+ & 197 & 85 & 260 & 65 & $331 \dagger \dagger$ & 99 & 324†† & 147 \\
\hline
\end{tabular}

AOM, azoxymethane.

Mean values were significantly different from those of the probiotic group: ${ }^{*} P<0.05$.

Mean value was significantly different from those of the control group: $\dagger+P<0.01$

Mean values were significantly different from those of the AOM-treated group: $\ddagger P<0.05$.

$\S$ Rats were non-exposed (four to five per group) or exposed to the carcinogen AOM (fifteen per group) at the beginning of the dietary treatment. For details of diets and procedures, see p. 932. 
Table 3. $\mathrm{CD}^{+}: \mathrm{CD}^{+}$ratio of lymphocytes (\%) isolated from spleen and mesenterial lymph nodes from rats fed for 33 weeks with a probiotic, prebiotic, synbiotic or control dietł (Mean values and standard deviations)

\begin{tabular}{|c|c|c|c|c|c|c|c|c|}
\hline \multirow[b]{2}{*}{ AOM } & \multicolumn{2}{|c|}{ Control } & \multicolumn{2}{|c|}{ Probiotic } & \multicolumn{2}{|c|}{ Prebiotic } & \multicolumn{2}{|c|}{ Synbiotic } \\
\hline & Mean & $\mathrm{SD}$ & Mean & SD & Mean & $\mathrm{SD}$ & Mean & SD \\
\hline \multicolumn{9}{|c|}{ Spleen } \\
\hline- & $13 \cdot 5 \dagger \dagger$ & $2 \cdot 4$ & $10 \cdot 4 † \dagger$ & $2 \cdot 8$ & $7 \cdot 9^{\star *}$ & $1 \cdot 8$ & $9 \cdot 71 \dagger$ & $3 \cdot 3$ \\
\hline+ & $7 \cdot 6$ & $2 \cdot 8$ & $6 \cdot 1$ & $2 \cdot 2$ & $6 \cdot 0$ & 2.4 & $6 \cdot 2$ & $2 \cdot 1$ \\
\hline \multicolumn{9}{|c|}{ Mesenterial lymph nodes } \\
\hline- & 8.7†† & $2 \cdot 1$ & $6 \cdot 7$ & $1 \cdot 3$ & $7 \cdot 7 \dagger \dagger$ & 0.5 & 8.0† & $2 \cdot 0$ \\
\hline+ & $5 \cdot 1$ & $1 \cdot 7$ & $4 \cdot 8$ & $1 \cdot 3$ & 5.9 & $1 \cdot 1$ & 5.9 & $1 \cdot 3$ \\
\hline
\end{tabular}

AOM, azoxymethane.

Mean value was significantly different from that of the control group: ${ }^{* *} P<0.01$.

Mean value were significantly different from those of the AOM-treated group: $\dagger P<0.05,+\dagger P<0.01$.

$\ddagger$ Rats were non-exposed (four to five per group) or exposed to the carcinogen AOM (fifteen per group)

at the beginning of the dietary treatment. For details of diets and procedures, see p. 932.

alone was less active. Rats supplemented with PRO, PRE or SYN developed significantly less carcinomas than control rats.

In rats not exposed to the carcinogen the PRE supplementation significantly increased NK cell-like activity of splenocytes. Few studies have investigated the effects of PRE on the immune system. In mice, supplementation with the non-digestible oligosaccharides nigerooligosaccharides stimulated hepatic NK cell cytotoxicity (Murosaki et al. 2002), while inulin and oligofructose enhanced splenic NK cell function (Kelly-Quagliana et al. 2003), confirming the results of the present study. In vitro, nigerooligosaccharides also stimulated NK cell function, pointing to a direct effect of such oligosaccharides on NK cells via specific lectin-type receptors (Murosaki et al. 1999).

The AOM treatment itself significantly suppressed NK cytotoxicity in spleens and PP of control and in PROand PRE-supplemented rats. This suppression was prevented in the rats supplemented with SYN (spleens) and with SYN and PRE (PP). Although several studies have demonstrated that AOM treatment inhibits NK cell cytotoxic activity in splenocytes (Baten et al. 1989; Altmann \& Lala, 1994; Sekine et al. 1997; Exon \& South, 2003), our present study is the first to show that NK cell-like cytotoxicity is also suppressed by AOM in cells isolated from PP. Whether this suppression of NK-like cells in PP is involved in colon carcinogenesis is currently not known. However, the PRO L. casei Shirota enhanced the cytotoxicity of NK cells and delayed tumour onset in mice with normal NK cell functions, while in a NK cell-deficient mouse mutant it was not effective (Takagi et al. 2001). This suggests that the suppression of NK cell functions not only in spleen but also in PP may contribute to tumour growth. In the Min mouse model, supplementation with short-chain fructo-oligosaccharides reduced the occurrence of colon tumours and increased the number of PP in the GALT (Pierre et al. 1997). However, the cytotoxicity of NK cells in these PP was not measured.

Our present results indicate that the supplementation with SYN primarily affected the incidence of adenomas and carcinomas and NK cell-like function. In contrast to the effects of SYN, the long-term supplementation of
AOM-exposed rats with the two PRO strains had no significant effect on NK cell-like function and less significant effects on colon carcinoma numbers. Several other studies with PRO reported stimulation of NK cell cytotoxicity and/or delayed colon carcinogenesis (Singh et al. 1997; McIntosh et al. 1999; Takagi et al. 2001). However, these studies supplied only one PRO strain and for shorter supplementation periods than in the present study. A further point is that in the present study we used a highfat diet comparable to a western-type diet, which at least in human subjects is known to suppress NK cell cytoxicity (Barone et al. 1989). The standard rat chow, however, is a low-fat diet. In another animal study only L. rhamnosus treatment significantly increased NK cell activity, while B. lactis had no significant effect (Gill et al. 2000). Since we used both lactic acid bacteria strains in combination, this may have impeded the enhanced NK cell cytotoxicity observed with L. rhamnosus alone. NK cell-like cytotoxicity of MLN cells was not affected by the dietary supplementation. After short-term supplementation, no effect was observed in this tissue either (Roller et al. 2004), suggesting that NK cells in these lymph nodes are not responsive to this dietary treatment. We do not have an explanation for the decline of splenic NK cell-like activity in the SYN-supplemented rats not treated with AOM.

Cytokine production in GALT was modulated by the dietary supplements. PRE and SYN supplementation significantly stimulated IL-10 production by PP cells in AOM-treated rats. Recently, $\mathrm{CD} 4{ }^{+} \mathrm{CD} 25^{+}$regulatory lymphocytes have been shown to require IL-10 to interrupt colon carcinogenesis in mice (Erdman et al. 2003). Short-term exposure to the same PRE also enhanced IL10 production in PP (Roller et al. 2004). A recent study reported enhanced IL-10 production by PP cells after feeding of fructooligosaccharide to mice (Hosono et al. 2003), confirming the results of the present study. Feeding the non-digestible oligosaccharide raffinose to mice further resulted in increased IL-12 production in PP (Nagura et al. 2002), and this is known to enhance IFN- $\gamma$ production in PP (MacDonald \& Monteleone, 2001) as well as NK cell cytotoxicity (Trinchieri, 1995). Incubation of PP cells with raffinose in vitro did not increase IFN- $\gamma$ or IL-12 production, suggesting that in vivo indirect effects 
of raffinose (e.g. butyrate production, altered intestinal microflora) mediate the observed effects. In contrast to PP, cytokine secretion of splenocytes was not modulated by the dietary treatment. In MLN, however, PRE and SYN supplements stimulated IL-10 production in rats not treated with AOM.

While supplementation with PRE or SYN primarily stimulated the immune functions of GALT, PRO supplementation inhibited IFN- $\gamma$ production by PP of rats not treated with AOM. Immune cells with the capacity to produce IFN- $\gamma$ include NK cells, which occur as subtypes with high cytotoxic-low IFN- $\gamma$-producing capacity $\left(\mathrm{CD} 56^{\mathrm{dim}}\right)$ and low cytotoxic-high IFN-producing capacity (CD56 ${ }^{\text {bright }}$ ) (Cooper et al. 2001). Since in rats $(-\mathrm{AOM})$ in the present study supplemented with the two PRO strains NK cell-like cytotoxicity was high, the PRO supplement may have induced a shift in the NK subtypes towards cells with a higher cytotoxic and a lower IFN- $\gamma$-producing capacity. In another study, nigerooligosaccharides stimulated the lytic function of hepatic NK cells, but not IFN- $\gamma$ secretion (Murosaki et al. 2002). Oral exposure of mice to yoghurt lactic acid bacteria $(L$. bulgaricus, $S$. thermophilus) had no effect on basal IFN- $\gamma$ mRNA expression in PP (Tejada-Simon et al. 1999). Taken together, these results are in accordance with the present data. Feeding mice with L. rhamnosus for 4 weeks significantly increased IFN- $\gamma$ production by splenocytes, while feeding $B$. lactis had no significant effect (Gill et al. 2000). Since we have used both lactic acid bacteria strains in combination, again this may have impeded enhanced IFN- $\gamma$ production by splenocytes in our present study. The increased IL-10:IFN- $\gamma$ ratio for the PP cells of SYN-supplemented rats suggests that the combined application of PRO and PRE shifts the Th1:Th2 balance towards a more anti-inflammatory response in GALT.

AOM treatment significantly reduced the CD4:CD8 ratio in spleen and MLN primarily by increasing the percentage of $\mathrm{CD}^{+}$lymphocytes. In spleens of rats not treated with AOM, the PRE supplement further decreased the CD4:CD8 ratio. Contradictory results were recently reported demonstrating in mice that feeding fructooligosaccharides for 2 weeks had no influence on the CD4:CD8 ratio in PP (Manhart et al. 2003). In mice, feeding lactic acid bacteria for 4 weeks had no significant effect on the percentages of $\mathrm{CD}^{+}$and $\mathrm{CD} 8^{+}$cells in the blood (Gill et al. 2000). Together these results suggest that PRO and PRE have only minor effects on the composition of $\mathrm{T}$ cell subsets in different immune compartments.

The capacity of lymphocytes isolated from spleen and MLN to proliferate following mitogen activation was clearly not affected by the dietary treatment. However, supplementation with SYN reduced lymphocyte proliferation in PP. This is in contrast to results from animal studies with strains of lactic acid bacteria that showed that feeding yoghurt (about $1.4 \times 10^{9}$ bacteria/d) or pure bacteria resulted in significantly higher proliferative responsiveness of lymphocytes to concanavalin A (Gill et al. 2000; Aattouri et al. 2002). Again, differences in the composition of the control diets may explain the differing outcomes of these studies.
The mechanisms by which PRO, PRE and SYN act on GALT and on tumourigenesis are not clear. Besides the direct immunological effects of PRO that have been demonstrated in a number of studies (Gill \& Cross, 2002), PRE may affect the immune system by several ways. First, PRE may induce a shift in the intestinal microflora towards bifidobacteria changing the antigen pattern of the intestinal microflora (Teitelbaum \& Walker, 2002). Second, we have shown that supplementing the rat feed with PRO increased the production of SCFA, such as butyrate, in the caecum (Femia et al. 2002). Butyrate is known to suppress lymphocyte proliferation, to inhibit cytokine production of Th1 lymphocytes, and to up-regulate IL-10 production (Säemann et al. 2000; Cavaglieri et al. 2003).

In conclusion, the reduced number of AOM-induced colon carcinomas in rats supplemented with PRO, PRE or SYN coincided with a marked stimulation of immune functions within the GALT. The present results clearly suggest that PP is the primary lymphoid tissue responsive to the oral intake of PRE or SYN. Whether this modulation of PP cells is associated with the suppression of carcinogenesis in the colon and the underlying mechanisms have to be determined in future studies.

\section{Acknowledgements}

We gratefully acknowledge the excellent technical assistance of Gisela Schultheiss, Marina Giorgi-Kotterba and Susanne Merkel. We thank L. Korn for the statistical consultation. The study was supported by the Commission of the European Communities, project no. QLKI-1999-00346.

\section{References}

Aattouri N, Bouras M, Tome D, Marcos A \& Lemonnier D (2002) Oral ingestion of lactic-acid bacteria by rats increases lymphocyte proliferation and interferon- $\gamma$ production. $\mathrm{Br} J \mathrm{Nutr} \mathbf{8 7}$, 367-373.

Altmann GG \& Lala PK (1994) Initiated stem cells in murine intestinal carcinogenesis: prolonged survival, control by $\mathrm{NK}$ cells, and progression. Int J Cancer 59, 569-579.

American Institute of Nutrition (1977) Report of the American Institute of Nutrition ad hoc committee on standards for nutritional studies. J Nutr 107, 1340-1348.

Barone J, Hebert JR \& Reddy MM (1989) Dietary fat and naturalkiller-cell activity. Am J Clin Nutr 50, 861-867.

Baten A, Ullah A, Tomazic VJ \& Shamsuddin AM (1989) Inositol-phosphate-induced enhancement of natural killer cell activity correlates with tumor suppression. Carcinogenesis $\mathbf{1 0}$, $1595-1598$.

Cavaglieri CR, Nishiyama A, Fernandes LC, Curi R, Miles EA \& Calder PC (2003) Differential effects of short-chain fatty acids on proliferation and production of pro- and anti-inflammatory cytokines by cultured lymphocytes. Life Sci 73, $1683-1690$.

Chang L, Gusewitch GA, Chritton DBW, Folz JC, Lebeck NK \& Nehlsen-Cannarella SL (1993) Rapid flow cytometric assay for the assessment of natural killer cell activity. J Immunol Methods 166, 45-54.

Cooper MA, Fehniger TA \& Caligiuri MA (2001) The biology of human natural killer-cell subsets. Trends Immunol 22, 633-640. 
Cross ML (2002) Microbes versus microbes: immune signals generated by probiotic lactobacilli and their role in protection against microbial pathogens. FEMS Immunol Med Microbiol 34, 245-253.

De Roos NM \& Katan MB (2000) Effects of probiotic bacteria on diarrhea, lipid metabolism, and carcinogenesis: a review of papers published between 1988 and 1998. Am J Clin Nutr 71, 405-411.

Erdman SE, Rao VP, Poutahidis T, Ihrig MM, Ge Z, Feng Y, Tomczak M, Rogers AB, Horwitz BH \& Fox JG (2003) $\mathrm{CD} 4{ }^{+} \mathrm{CD} 25^{+}$regulatory lymphocytes require interleukin 10 to interrupt colon carcinogenesis in mice. Cancer Res 63, 6042-6050.

Exon JH \& South EH (2003) Effects of sphingomyelin on aberrant colonic crypt foci development, colon crypt cell proliferation and immune function in an aging rat tumor model. Food Chem Toxicol 41, 471-476.

Femia AP, Luceri C, Dolara P, Giannini A, Biggeri A, Salvadori M, Clune Y, Collins KJ, Paglierani M \& Caderni G (2002) Antitumorigenic activity of the prebiotic inulin enriched with oligofructose in combination with the probiotics Lactobacillus rhamnosus and Bifidobacterium lactis on azoxymethaneinduced colon carcinogenesis in rats. Carcinogenesis 23, $1953-1960$.

Gill HS \& Cross ML (2002) Probiotics and immune function. In Nutrition and Immune Function, pp. 251-272 [PC Calder, CJ Field and HS Gill, editors]. Wallingford, Oxon: CAB International.

Gill HS, Rutherfurd KJ \& Cross ML (2001) Dietary probiotic supplementation enhances natural killer cell activity in the elderly: an investigation of age-related immunological changes. J Clin Immunol 21, 264-271.

Gill HS, Rutherfurd KJ, Prasad J \& Gopal PK (2000) Enhancement of natural and acquired immunity by Lactobacillus rhamnosus (HN001), Lactobacillus acidophilus (HN017) and Bifidobacterium lactis (HN019). Br J Nutr 83, 167-176.

Greenwald P, Clifford CK \& Milner JA (2001) Diet and cancer prevention. Eur J Cancer 37, 948-965.

Hosono A, Ozawa A, Kato R, Ohnishi Y, Nakanishi Y, Kimura T \& Nakamura R (2003) Dietary fructooligosaccharides induce immunoregulation of intestinal $\operatorname{IgA}$ secretion by murine Peyer's patch cells. Biosci Biotechnol Biochem 67, $758-764$.

Imai K, Matsuyama S, Miyake S, Suga K \& Nakachi K (2000) Natural cytotoxic activity of peripheral-blood lymphocytes and cancer incidence: an 11-year follow-up study of a general population. Lancet 356, 1795-1799.

Kelly-Quagliana KA, Nelson PD \& Buddington RK (2003) Dietary oligofructose and inulin modulate immune functions in mice. Nutr Res 23, 257-267.

MacDonald TT \& Monteleone G (2001) IL-12 and Th1 immune responses in human Peyer's patches. Trends Immunol 22 244-247.

McIntosh GH, Royle PJ \& Playne MJ (1999) A probiotic strain of L. acidophilus reduces DMH-induced large intestinal tumors in male Sprague-Dawley rats. Nutr Cancer 35, 153-159.

Manhart N, Spittler A, Bergmeister H, Mittlböck M \& Roth E (2003) Influence of fructooligosaccharides on Peyer's patch lymphocyte numbers in healthy and endotoxemic mice. Nutrition 19, 657-660.

Murosaki S, Muroyama K, Yamamoto Y, Kusaka H, Liu T \& Yoshika Y (1999) Immunopotentiating activity of nigerooligosaccharides for the $\mathrm{T}$ helper 1-like immune response in mice. Biosci Biotechnol Biochem 63, 373-378.

Murosaki S, Muroyama K, Yamamoto Y, Liu T \& Yoshika Y (2002) Nigerooligosaccharides augments natural killer activity of hepatic mononuclear cells in mice. Int Immunopharmacol 2, 151-159.

Nagura T, Hachimura S, Hashiguchi M, Ueda Y, Kanno T, Kikuchi H, Sayama K \& Kaminogawa S (2002) Suppressive effect of dietary raffinose on T-helper 2 cell-mediated immunity. $\mathrm{Br} \mathrm{J}$ Nutr 88, 421-426.

Pierre F, Perrin P, Champ M, Bornet F, Meflah K \& Menanteau J (1997) Short-chain fructo-oligosaccharides reduce the occurrence of colon tumors and develop gut-associated lymphoid tissue in Min mice. Cancer Res 57, 225-228.

Pool-Zobel BL, van Loo J, Rowland IR \& Roberfroid MB (2002) Experimental evidences on the potential of prebiotic fructans to reduce the risk of colon cancer. Brit J Nutr 87, Suppl. 2, S273-S281.

Reddy BS (1998) Prevention of colon cancer by pre- and probiotics: evidence from laboratory studies. Br J Nutr 80, Suppl. 7, S219-S223.

Reddy BS (1999) Possible mechanisms by which pro- and prebiotics influence colon carcinogenesis and tumor growth. $J$ Nutr 129, Suppl. 7, 1478S-1482S.

Roller M, Rechkemmer G \& Watzl B (2004) Prebiotic inulin enriched with oligofructose in combination with the probiotics Lactobacillus rhamnosus and Bifidobacterium lactis modulates intestinal immune functions in rats. $J$ Nutr 134, 153-156.

Säemann MD, Böhmig GA, Österreicher $\mathrm{CH}$, Burtscher $\mathrm{H}$, Parolini O, Diakos C, Stöckl J, Hörl WH \& Zlabinger GJ (2000) Anti-inflammatory effects of sodium butyrate on human monocytes: potent inhibition of IL-12 and up-regulation of IL-10 production. FASEB $J \mathbf{1 4}, 2380-2382$.

Schley PD \& Field CJ (2002) The immuno-enhancing effects of dietary fibres and prebiotics. Br J Nutr 87, Suppl. 2, S221-S230.

Sekine K, Ushida Y, Kuhara T, Iigo M, Baba-Toriyama H, Moore MA, Murakoshi M, Satomi Y, Nishino H, Kakizoe T, et al. (1997) Inhibition of initiation and early stage development of aberrant crypt foci and enhanced natural killer activity in male rats administered bovine lactoferrin concomitantly with azoxymethane. Cancer Lett 121, 211-216.

Singh J, Rivenson A, Tomita M, Shimamura S, Ishibashi N \& Reddy BS (1997) Bifidobacterium longum, a lactic acid-producing intestinal bacterium, inhibits colon cancer and modulates the intermediate biomarkers of colon cancer. Carcinogenesis 18, 833-841.

Smyth MJ, Godfrey DI \& Trapani JA (2001) A fresh look at tumor immunosurveillance and immunotherapy. Nat Immunol 2, 293-299.

Takagi A, Matsuzaki T, Sato M, Nomoto K, Morotomi M \& Yokokura T (2001) Enhancement of natural killer cytotoxicity delayed murine carcinogenesis by a probiotic microorganism. Carcinogenesis 22, 599-605.

Tartter PI, Steinberg B, Barron DM \& Martinelli G (1987) The prognostic significance of natural killer cytotoxicity in patients with colorectal cancer. Arch Surg 122, 1264-1268.

Teitelbaum JE \& Walker WA (2002) Nutritional impact of preand probiotics as protective gastrointestinal organisms. Annu Rev Nutr 22, 107-138.

Tejada-Simon MV, Ustunol Z \& Pestka JJ (1999) Effects of lactic acid bacteria ingestion on basal cytokine mRNA and immunoglobulin levels in the mouse. J Food Protect 62, 287-291.

Trinchieri G (1995) Interleukin-12: a proinflammatory cytokine with immunoregulatory functions that bridge innate resistance and antigen-specific adaptive immunity. Annu Rev Immunol 13, 251-276.

Van Loo J, Cummings JH, Delzenne N, Englyst HN, Franck A, Hopkins MJ, Kok N, Macfarlane GT, Newton DF, Quigley 
ME, et al. (1999) Functional food properties of non-digestible oligosaccharides: a consensus report from the ENDO project (DGXII AIRII-CT94-1095). Br J Nutr 81, 121-132.

Verghese M, Rao DR, Chawan CB, Williams LL \& Shackelford L (2002) Dietary inulin suppresses azoxymethane-induced aberrant crypt foci and colon tumors at the promotion stage in young Fisher 344 rats. J Nutr 132, 2809-2813.
Watzl B, Neudecker C, Hänsch GM, Rechkemmer G \& Pool-Zobel BL (1999) Short-term moderate aflatoxin $B_{1}$ exposure has only minor effects on the gut-associated lymphoid tissue of Brown Norway rats. Toxicology 138, 93-102.

Wollowski I, Rechkemmer G \& Pool-Zobel BL (2001) Protective role of probiotics and prebiotics in colon cancer. Am J Clin Nutr 73, 451S-455S. 